\title{
Topical Application Effect of the Isolectin Hydrogel (Cramoll 1,4) on Second-Degree Burns: Experimental Model
}

\author{
Danielle dos Santos Tavares Pereira, ${ }^{1}$ Maria Helena Madruga Lima-Ribeiro, ${ }^{2,3}$ \\ Ralph Santos-Oliveira, ${ }^{4}$ Carmelita de Lima Bezerra Cavalcanti, ${ }^{3}$ \\ Nicodemos Teles de Pontes-Filho, ${ }^{5}$ Luana Cassandra Breitenbach Barroso Coelho, ${ }^{6}$ \\ Ana Maria dos Anjos Carneiro-Leão, ${ }^{4}$ and Maria Tereza dos Santos Correia ${ }^{1,6}$ \\ ${ }^{1}$ Programa de Pós-Graduação em Ciências Biológicas, Universidade Federal de Pernambuco, 50670-901 Recife, PE, Brazil
2Programa de Pós-Graduação em Biociência Animal, Universidade Federal Rural de Pernambuco, 52171-900 Recife, PE, Brazil
${ }^{3}$ Laboratório de Imunopatologia Keizo Asami (LIKA), Universidade Federal de Pernambuco, 50670-901 Recife, PE, Brazil
${ }^{4}$ Divisão de Radiofarmácia, Instituto de Engenharia Nuclear, 21941-906 Rio de Janeiro, RJ, Brazil
${ }^{5}$ Departamento de Patologia, Universidade Federal de Pernambuco, 50670-901 Recife, PE, Brazil
${ }^{6}$ Departamento de Bioquímica, Centro de Ciências Biológicas, Universidade Federal de Pernambuco, 50670-901 Recife, PE, Brazil
}

Correspondence should be addressed to Danielle dos Santos Tavares Pereira, dstpereira@yahoo.com.br

Received 24 August 2011; Revised 31 October 2011; Accepted 8 November 2011

Academic Editor: Monica Fedele

Copyright (C) 2012 Danielle dos Santos Tavares Pereira et al. This is an open access article distributed under the Creative Commons Attribution License, which permits unrestricted use, distribution, and reproduction in any medium, provided the original work is properly cited.

\begin{abstract}
This study aimed at evaluating the use of hydrogel isolectin in the treatment of second-degree burns. Twenty male rats were randomly divided into two groups ( $\mathrm{G} 1=$ treatment with hydrogel containing $100 \mu \mathrm{g} / \mathrm{mL}$ Cramoll 1,4 and G2= Control, hydrogel). After 7, 14, 21, 28, and 35 days, animals were euthanized. On the 7th day, G1 showed intense exudates, necrosis and edema. On the 14th day, G1 showed tissue reepithelialization and moderate autolysis. On the 21st day, G1 showed intense fibroblastic proliferation, presence of dense collagen, and moderate fibrosis. On the 28th day, G1 showed complete tissue epithelialization. On the 35th day, G1 showed modeled dense collagen. The significant wound contraction was initiated from day, 14 in the G1. There were no significant differences in biochemical and hematological parameters analyzed. These results extend the potential of therapeutic applications for Cramoll 1,4 in the treatment of thermal burns.
\end{abstract}

\section{Introduction}

Since prehistory, plants and their by-products were used to treat wounds. Cramoll 1.4 is lectin extracted from seeds of Cratylia mollis Mart, a plant native to northeastern Brazil. Cramoll is specific for glucose/mannose. Four multiple forms have been purified from C. mollis-Cramoll 1, Cramoll 2, Cramoll 3, Cramoll 4-and preparations containing multiple combined forms as 1 and 4, named Cramoll 1.4 [2]. Studies have demonstrated that Cramoll 1,4 is capable of (i) isolating glycoproteins from human plasma [3], (ii) characterizing transformed mammary tissue [4], (iii) inducing mitogenic activity in human lymphocytes [5], (iv) producing IFN-y and nitric oxide [6], and (v) antitumor activities [7].
Burn wounds are one of the health problems in modern societies associated with irreparable harms and side many problems for patients and their families [8]. Burns are classified by their depth and severity such as 1st, 2nd, 3rd, and 4th degrees. The pathophysiologic reaction to a burn injury is complex and varies with the cause (thermal, chemical, electrical, or radiation). In thermal injuries, changes in the burn wound are mainly caused by heat direct effects, but superimposed on these are changes associated with the acute inflammatory process. It is these latter changes that account for the widespread and devastating effects of major burns on the entire body's homeostatic function [9]. In addition to the physiological morbidity of burns, these types of injuries are associated with a huge financial burden on the public health system. 
In order to ease the pain of burning and minimize the number of dressing changes, several studies have been carried out in search of formulations that help in healing. The advent of dry bandages occurred in the nineteenth century due to the germ theory authored by Louis Pasteur. In the twentieth century, with advances in knowledge about the mechanisms involved in tissue lesion healing, the theory that the wounds in a wet environment have better healing capacity was developed [10]. In order to meet this need, the wet bandages containing natural and synthetic molecules have shown significant effect on the healing mechanism. In this sense, aiming to evaluate the effects of topical application of hydrogel containing 1, 4 Cramoll isolectin, this study investigated in vivo the clinical and histopathological features of seconddegree thermal burns demonstrated experimentally in rats of Wistar strain.

\section{Materials and Methods}

\subsection{Plant Material}

2.1.1. Cratylia Mollis (Extraction and Purification). Cramoll 1,4 isolectin was purified from a $10 \%(\mathrm{w} / \mathrm{v})$ seed extract of Cratylia mollis in $0.15 \mathrm{M} \mathrm{NaCl}$ according to the protocol reported in Correia and Coelho [11]. Briefly, all seeds (Camaratu bean) collected in Ibimirim City, State of Pernambuco, were washed with distilled water, dried at room temperature, and blended in $0.15 \mathrm{M} \mathrm{NaCl}$. After $16 \mathrm{~h}$ of gently stirring at $4^{\circ} \mathrm{C}$, the extract was filtered and centrifuged for $12000 \mathrm{~g}$. The extract was ammonium sulfate fractionated, dialysed against $0.15 \mathrm{M} \mathrm{NaCl}$ (fraction 40-60\%) and affinity chromatographed on Sephadex G-75 (Sigma Chemical Company) in column $(70.0 \times 1.9 \mathrm{~cm})$ containing $200 \mathrm{~mL}$ packed matrix, balanced with $0.15 \mathrm{M} \mathrm{NaCl}$. After sample application, $0.15 \mathrm{M} \mathrm{NaCl}$ was passed through the column until $A 280 \mathrm{~nm}$ was less than 0.1 ; isolectin was eluted with $0.3 \mathrm{M}$ glucose in $0.15 \mathrm{M} \mathrm{NaCl}$. Fractions with highest $A 280 \mathrm{~nm}$ were pooled, exhaustively dialysed in buffer citrate phosphate and then lyophilized. The native isolectin has $8.5-8.6 \mathrm{pI}$ measured by isoelectric focusing in polyacrylamide gel and $31 \mathrm{Kda}$ main polypeptide.

2.2. Isolectin Hydrogel. Carbopol was used as vehicle suspended in boric acid buffer $(\mathrm{pH} 6.0)$ at $25^{\circ} \mathrm{C}$. After extraction and purification, Cramoll 1,4 solutions were added in sufficient quantity to achieve the final concentration of $100 \mu \mathrm{g}$ Cramoll 1,4 per $\mathrm{mL}$ of hydrogel. Irradiation was performed at room temperature using $\mathrm{Co}^{60}$ at $15 \mathrm{kGy} \mathrm{h}^{-2}$ [12].

2.2.1. Evaluation of Hemagglutinating Activity of the Isolectin Hydrogel. The hemagglutinating activity was performed in microtiter plates according to Correia and Coelho [11]. Samples of isolectin hydrogel $(50 \mu \mathrm{L})$ were serially diluted in $0.15 \mathrm{M} \mathrm{NaCl}$ before adding $5 \mu \mathrm{L}$ of a $2.5 \%(\mathrm{v} / \mathrm{v})$ rabbit erythrocytes suspension previously treated with glutaraldehyde. The title was expressed as the highest dilution showing hemagglutinating activity. Assay performed in triplicate.

\subsection{Animals and Experimental Wounds}

2.3.1. Animals. All animals received humane care, and studies reported in this paper have been carried out in accordance with the guidelines for human treatment of animals set by the Brazilian College of Animal Experiment. The study was approved by the Committee on Animal Research at the Federal University of Pernambuco, Brazil (23076.015015/2009-31). A total of twenty male Wistar rats (Rattus norvegicus, albinus), 8-10-week-old and weighing approximately 250-300 g, were used in this study. Food pellets and water were provided ad libitum throughout the experiment.

2.3.2. Burn Injury. Animals were divided randomly into two groups of 10 (G1 and G2) and preanesthetized with atropine sulfate at $0.04 \mathrm{mg} \mathrm{kg}^{-1}$ intramuscularly. After ten minute, an anesthetic combination was used through an intramuscular injection of xylazine $10 \mathrm{mg} \mathrm{kg}^{-1}$ and ketamine $90 \mathrm{mg} \mathrm{kg}^{-1}$ with subsequent dorsum trichotomy by direct hair tension (area measuring approximately $3 \mathrm{~cm}^{2}$ ) (Figure $1(\mathrm{a})$ ) and antisepsis with $1 \%$ polyvinylpyrrolidone-iodine. Burns were symmetrically caused on depilated areas through contact with an aluminum bar $(r=10 \mathrm{~mm})$, preheated for $100^{\circ} \mathrm{C}$ for $15 \mathrm{~s}$ (Figure 1(b)). After burn injury and animal awakening, once the procedure completed, analgesia was processed by means of intramuscular dipyrane application $\left(0.01 \mathrm{mg} \mathrm{kg}^{-1}\right)$ to prevent pain. Injuries were observed during 35 consecutive days followed by the application of $100 \mu \mathrm{L}$ hydrogel on the burn (Figure 1(c)). Group-1 was treated with empty hydrogel containing $100 \mu \mathrm{g}$ Cramoll 1,4. Group-2 (control) was treated with hydrogel without isolectin.

\subsection{Pathological Observations}

2.4.1. Clinical Parameters. Burns surface was evaluated based on the following parameters for 35 consecutive days: edema, hyperemia, exudation and the firmness of wound surface, and presence or absence of granulation tissue and scar tissue. Wounds were considered closed if moist granulation tissue was no longer apparent and wounds seemed covered with new epithelium. Body weight was determined using electronic balance (accuracy to $\mathrm{g}$ ) on the day of burn induction as well as days $7,14,21,28$, and 35 after wounding.

2.4.2. Wound Retraction Quantification. All the rats were examined weekly under anesthesia for observation of wound contracture. The wound retraction was evaluated in 7, 14, 21, 28 , and 35 days after burn induction. Wound contraction was expressed as reduction in percentage of original wound size. $\%$ wound contraction on day-X $=[$ (area on day $0-$ open area on day X)/area on day 0] × 100 [13].

2.4.3. Biochemical and Hematological Evaluations. Blood from two animals per group were collected on days 7, $14,21,28$, and 35 after burn induction for biochemical determination. Levels of creatinine, urea, glutamic pyruvic transaminase, glutamic oxalacetic transaminase, gamma 


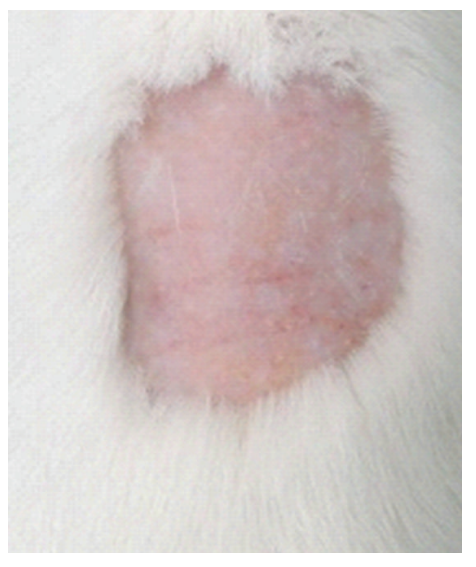

(a)

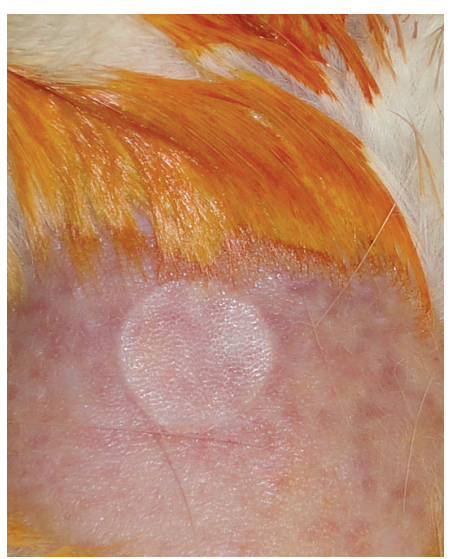

(b)

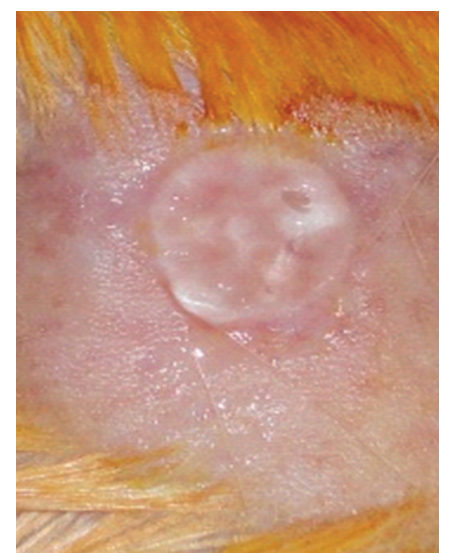

(c)

FIGURE 1: Induction of second-degree thermal burns in male Wistar rats. (a) Back trichotomy by direct hair tension, (b) depth second-degree thermal burn with $r=10 \mathrm{~mm}$, (c) treatment of thermal burn using $100 \mu \mathrm{L}$ hydrogel.

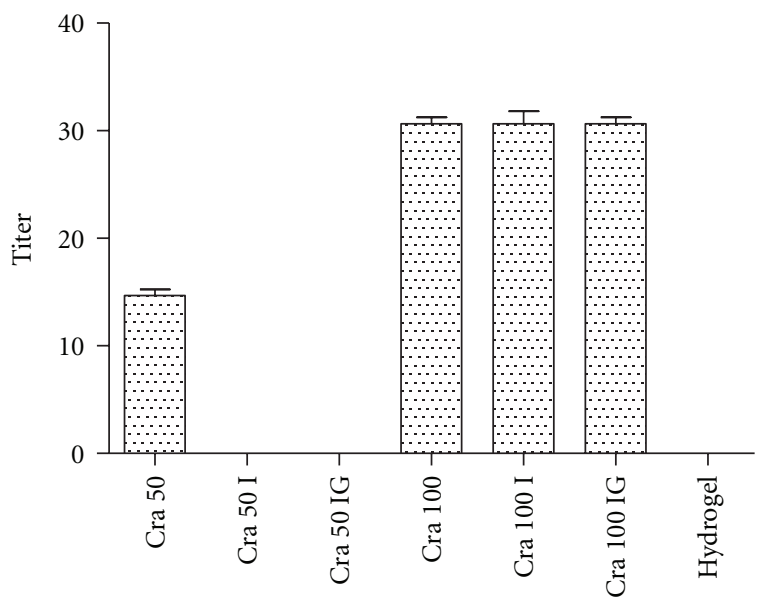

FIgURE 2: Evaluation of hemagglutinating activity of 1,4 Cramoll isolectin combined to the hydrogel excipient. Cra 50: Pure Cramoll 1,4 isolectin at $50 \mu \mathrm{g} / \mathrm{mL}$. Cra $50 \mathrm{I}$ : Pure Cramoll 1,4 isolectin at $50 \mu \mathrm{g} / \mathrm{mL}$ irradiated $\left(15 \mathrm{k} \mathrm{Gy} \mathrm{h}^{-2}\right)$. Cra IG: Pure Cramoll 1,4 isolectin at $50 \mu \mathrm{g} / \mathrm{mL}$ associated with hydrogel excipient and irradiated $\left(15 \mathrm{kGyh}^{-2}\right)$. Cra 100: Pure Cramoll 1,4 isolectin at $100 \mu \mathrm{g} / \mathrm{mL}$. Cra 100 I: Pure Cramoll 1,4 isolectin at $100 \mu \mathrm{g} / \mathrm{mL}$ irradiated $\left(15 \mathrm{kGyh}^{-2}\right)$. Cra IG 100: Pure Cramoll 1,4 isolectin at $100 \mu \mathrm{g} / \mathrm{mL}$ associated with hydrogel excipient and irradiated $\left(15 \mathrm{kGy} \mathrm{h}^{-2}\right)$. Hydrogel irradiated without lectin. The title was expressed as the highest dilution showing hemagglutinating activity. Values are mean \pm SEM.

glutamyl transferase, amylase, alkaline phosphatase, calcium, prothrombin, and fibrinogen were determined. Hematological parameters (erythrocytes, leukocytes, and platelets) were determined immediately after blood collection. Evaluations performed in triplicate. Animals in both G1 and G2 were sacrificed by injecting $30 \mathrm{mg} \mathrm{kg}^{-1}$ thiopental sodium.

2.4.4. Histopathology. After collection, tissue samples were fixed in $4 \%$ formaldehyde $(\mathrm{v} / \mathrm{v})$ prepared in PBS $(0.01 \mathrm{M}$,
$\mathrm{pH}$ 7.2) followed by histological processing through paraffin embedding, microtome with $4 \mu \mathrm{m}$ cuts, and Masson's trichrome and hematoxylin-eosin staining. Histological analysis was performed by comparative descriptive analysis of experimental groups in binocular optical microscope (Zeiss-Axiostar model), where cellular and tissue characteristics of skin were evaluated after thermal injury and subsequent healing pattern.

2.5. Statistical Analysis. Data were analyzed using nonparametric tests. To detect differences between groups, the MannWhitney $U$ test was used. All results were expressed as mean values of groups \pm standard deviation and analyzed considering $P<0.05$ as statistically significant.

\section{Results and Discussion}

Overall, all animals were clinically well (showing normal behavior of species and ingestion of food and water) during the experiments. There was no bleeding during surgery. Neither the rats under treatment nor the control group showed any statistically significant changes on the body weight throughout the experiments, showing that analgesia was adequate for the injury caused. As reported by Hellebrekers [1], the main signs of pain in laboratory animals subjected to experimental procedures are directly related to changes in behavior, with anorexia being one of the most significant signs.

3.1. Hemagglutinating Activity. Due to the immunostimulating and mitogenic activities attributed to lectins, the therapeutic use of these proteins in tissue repair processes has been subject of much research either related to the lectin concentration or the formulation used [14].

Lectins or hemagglutinins can be detected and characterized by their ability to agglutinate erythrocytes. In the evaluation of hydrogel containing 1,4 isolectin Cramoll was observed that Cramoll-1,4 at $50 \mu \mathrm{g} / \mathrm{mL}$ in both pure and 
G1

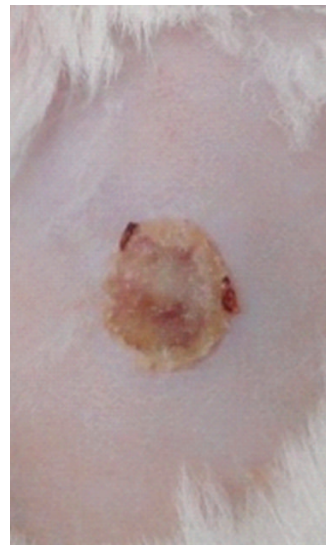

(a)

G2

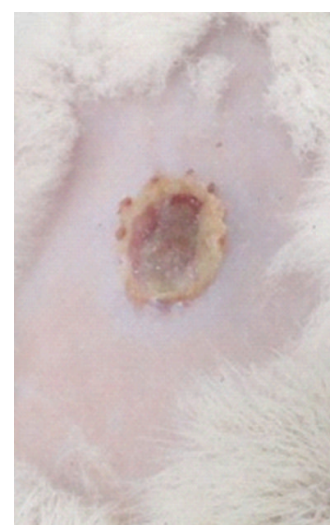

(f)

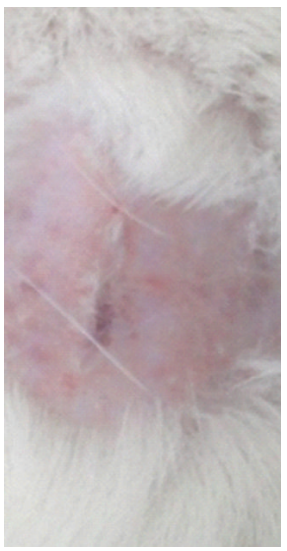

(b)

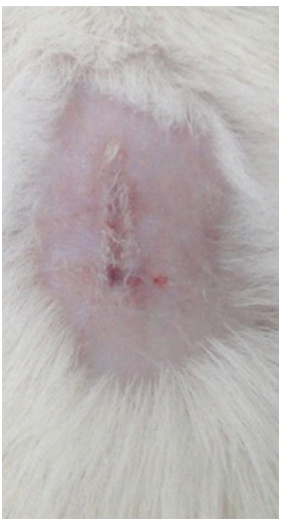

(g)

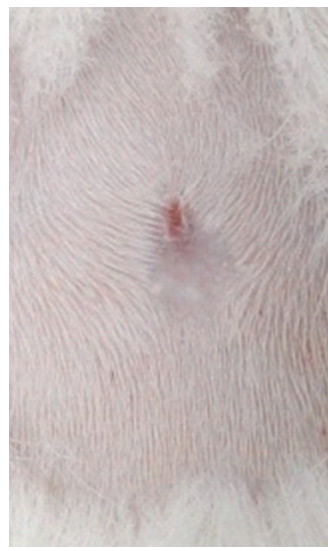

(c)

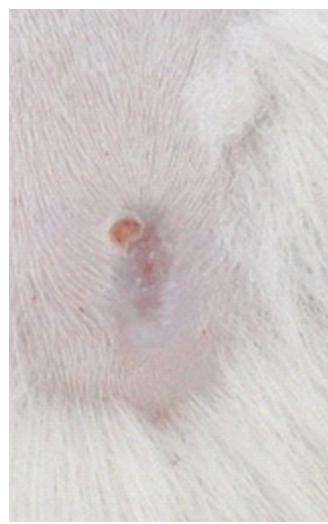

(h)

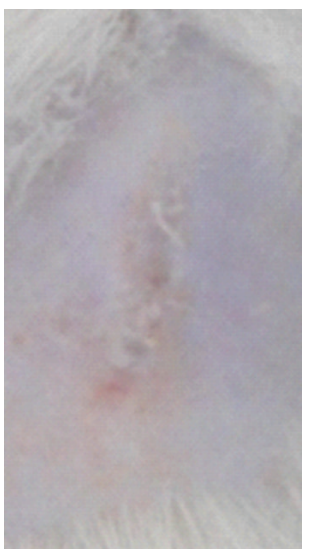

(d)

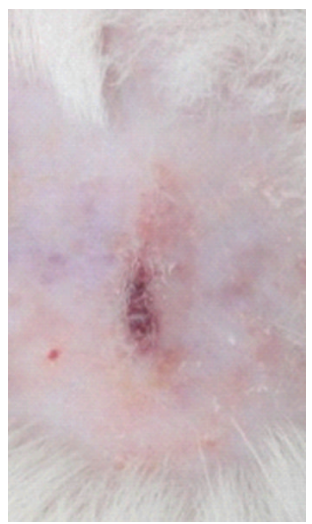

(i)

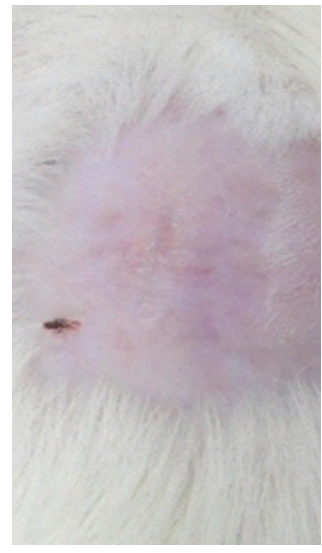

(e)

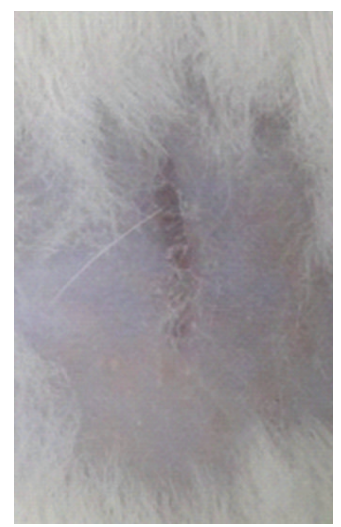

(j)

FIgURE 3: Clinical evaluation of second-degree burn healing in Wistar male rats. G1: experimental group treated with hydrogel containing isolectin Cramoll 1,4 at $100 \mu \mathrm{g} / \mathrm{mL}$. (a) Thermal lesion aspect after 7 days: macroscopically shows thin and dry crust with detachment of edges. (b) Thermal lesion aspect after 14 days of treatment: absence of crust and the presence of scar tissue. (c) Thermal lesion aspect after 21 days of treatment: presence of scar tissue and a small detachment point of the crust. (d) Thermal lesion aspect after 28 days of treatment: presence of scar tissue only. (e) Thermal lesion aspect after 35 days of treatment: view of a discrete scar tissue. G2: control group treated by topical application of hydrogel excipient. (f) Thermal lesion aspect in control animals after 7 days: view of thin and dry crust with detachment of edges. (g) Thermal lesion aspect in control animals after 14 days: absence of crust and the presence of scar tissue. (h) Thermal lesion aspect in control animals after 21 days: presence of scar tissue, with the point of detachment of the crust. (i) Thermal lesion aspect in control animals after 28 days: presence of scar tissue and a second crust. (j) Thermal lesion aspect in control animals after 35 days: view of scar tissue.

gel formulation after irradiation lost their hemagglutinating activity. On the other hand, the concentration $100 \mu \mathrm{g} / \mathrm{mL}$ remained constant for the irradiated pure isolectin and that combined to the hydrogel excipient (Figure 2).

Several aspects make the hydrogel an ideal bandage for treatment of tissue lesions, such as hydrophilicity, biocompatibility, nontoxicity, biodegradability, easy replacement, transparency, adhesion, absorption, and prevention of body fluid losses [15, 16]. Burd [17] evaluated the use of hydrogel sheet dressings in comprehensive burn wound care, noting that use of hydrogel in burn wound care reduces patient's pain sensation. Osti [18] evaluated the use of a transparent adhesive film possessing selective permeability combined with a hydrogel (Burnshield) in burns treatment. For about 2 years, this type of therapy was used in the first aid treatment of 48 burn patients, 4 were lost during therapy and 4 were unavailable for followingup. In the reepithelialization phase complications were recorded in 8 of the 40 patients: 7 (18\%) had residual inflammation and $1(2 \%)$ had hypertrophic scar. During the followup, late complications were recorded in 2 (5\%) of the 40 patients. A gel was used in 8 patients: in 6 of the 7 patients with residual inflammation, the complication was solved, while in 1, despite therapy, the residual inflammation evolved into hypertrophic scarring. 


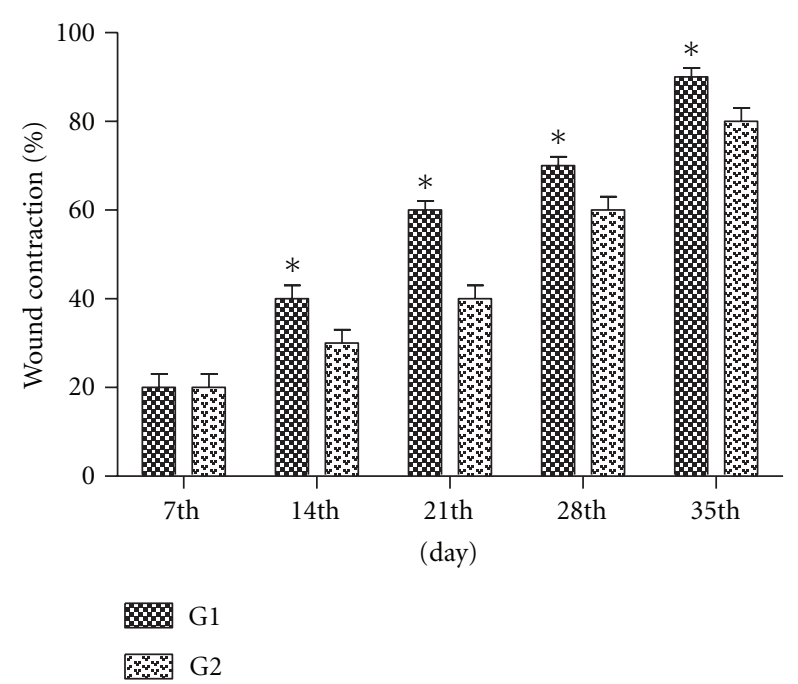

FIgURE 4: Effect of hydrogel topical application on the burn wound expressed as percentage of wound contraction. G1 = Treatment, $\mathrm{G} 2=$ Control. $n=2$. Values are mean \pm SEM. ${ }^{*} P<0.05$.

3.2. Clinical Parameters. Wound cooling caused by burn is an urgency measure, which proved to be beneficial in clinical and experimental practices. Hydrogels are crosslinking three-dimensional structures with high water percentage that can be transferred from the gel to the scar wound to facilitate hydration. The healing process of animals with aseptic experimental thermal burns treated topically with isolectin had better response than the control in the clinical examination in several ways such as (1) presence of edema in the first $24 \mathrm{~h}$ after induction of second-degree thermal burn, (2) thickening of the crust, which began to emerge spontaneously in 6 days of experiment, (3) discrete hyperemia observed in the range between 24 and $48 \mathrm{~h}$ after injury and (4) presence of scar tissue with 13 days of experiment (Figure 3). During the study period, lesions showed no signs of infection. Severely burned skin ceases to perform its natural protective and barrier role and allows a dramatic increase in water loss and can become a portal for bacterial invasion. The local treatment of second-degree burns is targeted at maintaining a wet microenvironment and stimulating the formation of a well-vascularised granulation tissue, and the reepithelization of the lesion while counteracting the development of microorganisms, which is able to delay or prevent the biological phenomena of cicatrization and reepithelization [19].

3.3. Wound Retraction Quantification. The wound contraction is a parameter used for assessing wound healing. The lesion area decreased gradually with the progress of healing time in both groups. The significant wound contraction was initiated from day 14 in the G1 that showed highest rate of lesion contraction compared with G2, indicating that isolectin has an inducing effect on the lesion contraction as illustrated in Figure 4. These results are consistent with studies in vitro and in vivo performed by Sezer et al. [20], which demonstrated the efficacy of hydrogels in the treatment of dermal burns in rabbit model revealing that the application of fucoidan-chitosan hydrogel promotes burn wound contraction and induces healing.

Wound contraction, wound shrinking process, depends on the tissue's reparative abilities, type, and damage extent and tissue health general state [21]. On the other hand, the wound contraction is rarely able to take to its permanent closure, which is mainly due to the presence of fibroblasts found in the granulation tissue that later differentiates into myofibroblasts [22].

3.4. Biochemical and Hematological Evaluation. Hematological values obtained in this study showed no significant changes as a function of burn induction during the period analyzed (erythrocytes: $7.6 \pm 0.48$, hemoglobin, $13.65 \pm 0.5$; platelets: $846400 \pm 0.71$, leukocytes: $7980 \pm 0.71$, basophils: $0.2 \pm 0.05$, eosinophils: $1.38 \pm 0.18$, lymphocytes: $82.37 \pm 0.83$, and Monocytes: $1.9 \pm 0.2$ ) (Table 1), revealing normal values in rats [23]. Rats, like other mammals, have to maintain strict control of the internal environment thus ensuring homeostasis. It is known that rats can produce changes in these parameters as a result of pathological processes or external factors such as sex, ancestry, age, diet, handling, and environment [24].

However, average values of biochemical parameters analyzed in this study were consistent with previously reported specific data to normal animals (calcium: $10.04 \pm 0.42$, proThrombin: $9.94 \pm 0.16$, fibrinogen: $457.32 \pm 0.25$, alkaline phosphatase: $212.68 \pm 0.52$, glutamic oxalic transaminase: $180.02 \pm 0.35$, glutamic pyruvic transaminase: $53.28 \pm 0.41$, gamma-glutamyl transpeptidase: $5.76 \pm 0.23$, creatine: $0.54 \pm$ 0.04, urea: $46.34 \pm 0.04$ and amylase: $842.06 \pm 0.48$ ) (Table 2). The biochemical evaluation revealed increased ALT levels in response to injury by burning and alkaline phosphataserelated to inflammatory period of the healing process. On the other hand, metabolic changes are considered high risk in third-degree burns with hyperglycemia [25] and high protein catabolism [26] as the main aggravating factors to the injury.

After burn trauma, inflammatory mediators, oxygen-free radicals, and arachidonic acid metabolites and complement [27], released in the wounds, promote a great edema. According to Beukelman et al. [28], liposomal hydrogel with 3\% povidone-iodine (PVP-ILH, Repithel) has shown clinical benefit in settings where inflammation and/or reactive oxygen species are thought to impede wound healing (e.g., burns and chronic wounds in smokers). According to Møller-Kristensen et al. [29], the MBL, mannan-binding lectin, modulates not only inflammatory factors such as cytokines and chemokines, but also cell adhesion molecules, the binding growth factor protein, and, MPPs in particular, metalloproteinase matrix, which are most likely the direct effectors in scabs detachment.

Considering the influence of carbohydrates in numerous cell signaling phenomena whether physiological or pathological, the use of lectins in the treatment of cutaneous lesions among other diseases stimulates the activation and modulation events such as communication, cellular differentiation, and proliferation [30-32]. 


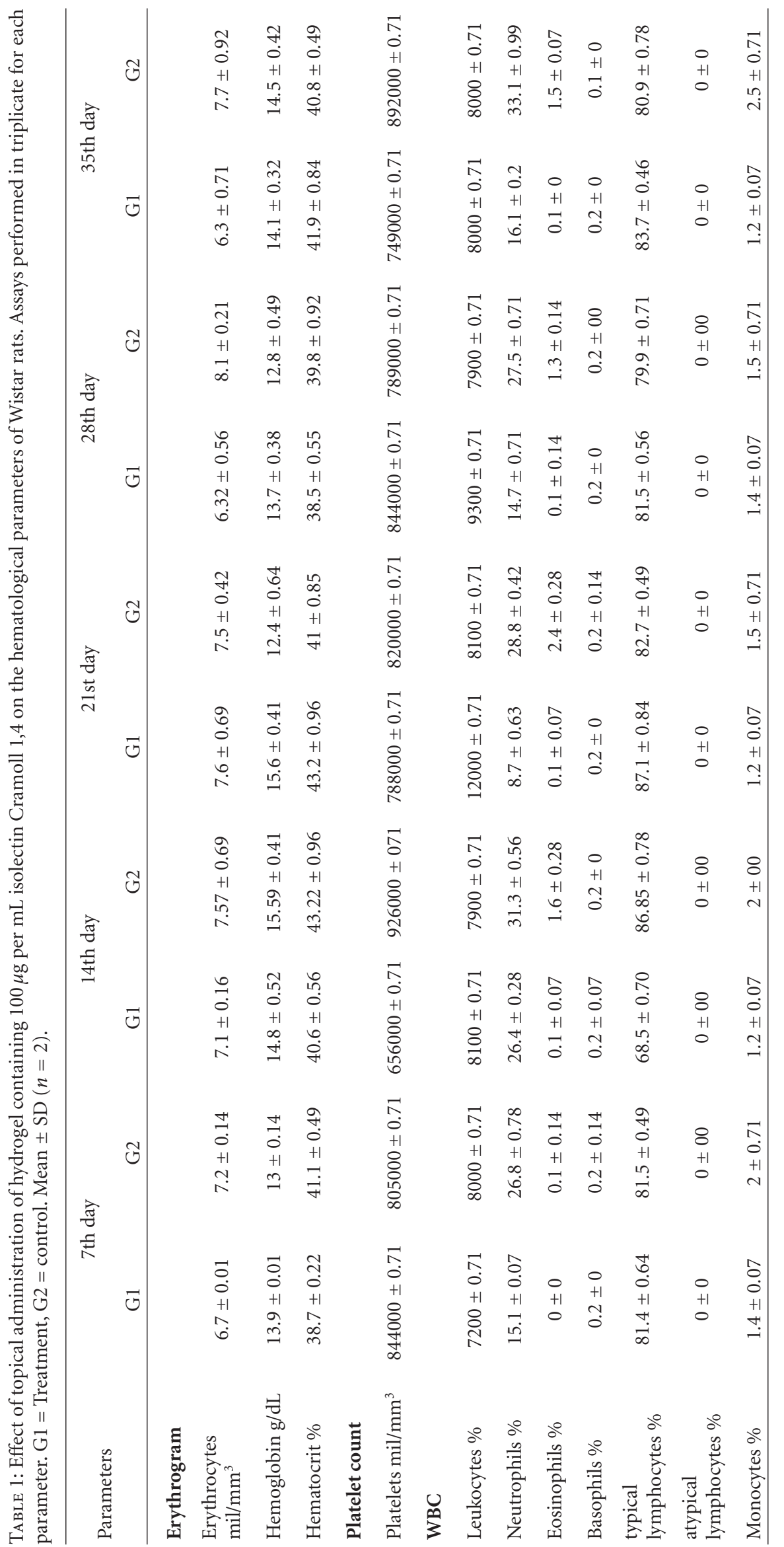




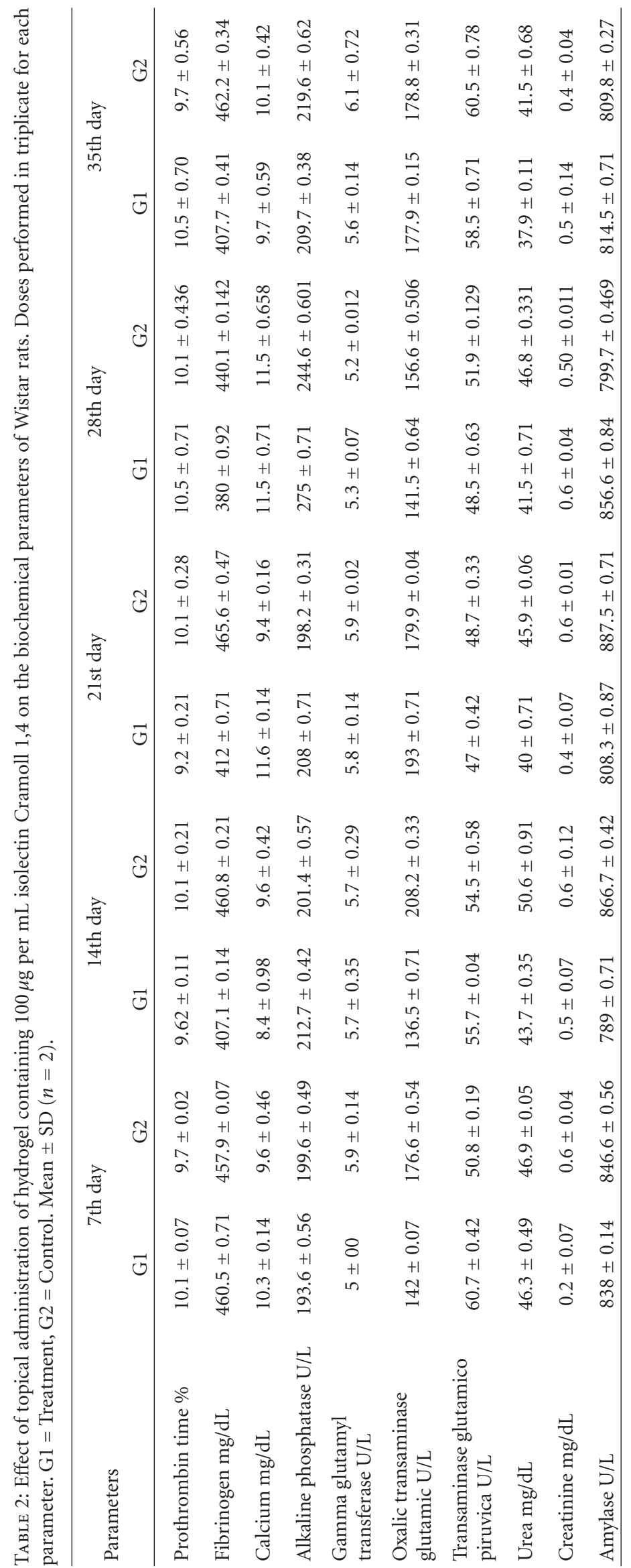




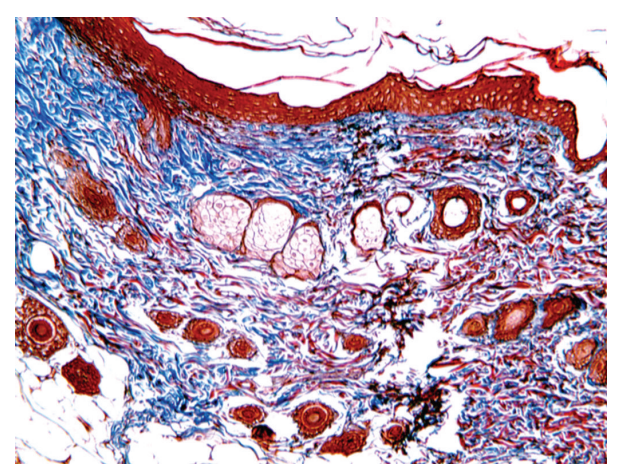

(a)

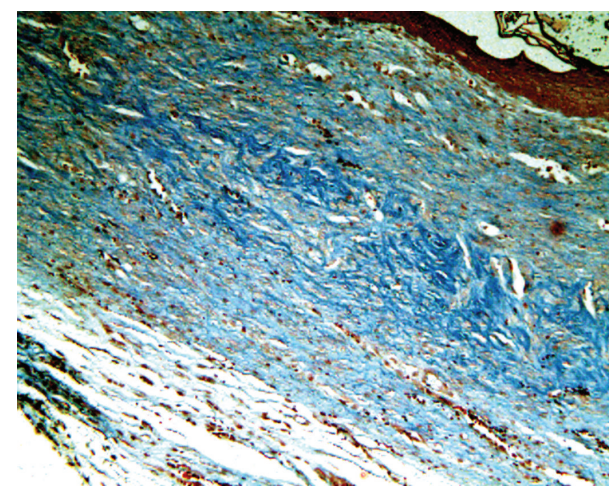

(c)

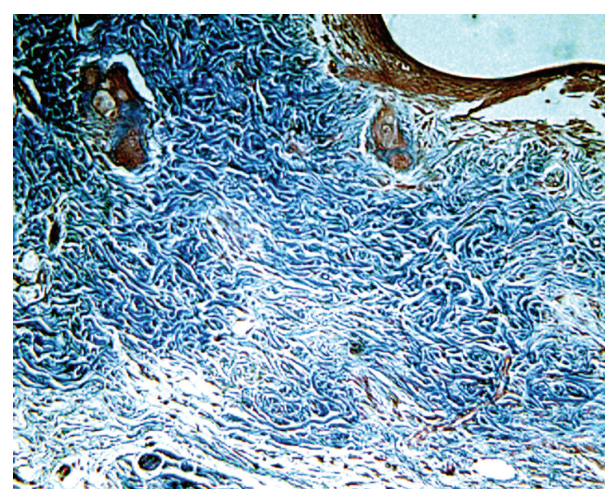

(e)

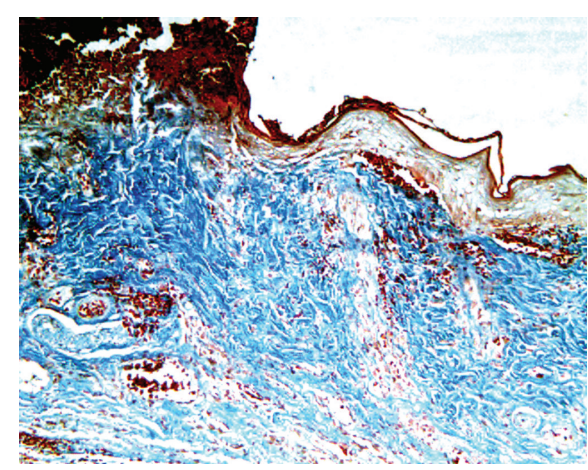

(b)

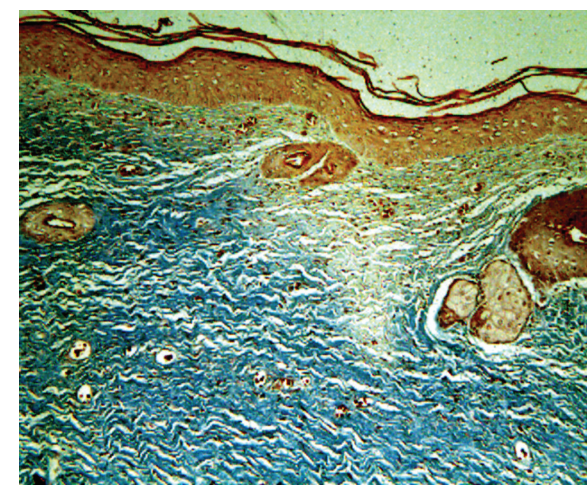

(d)

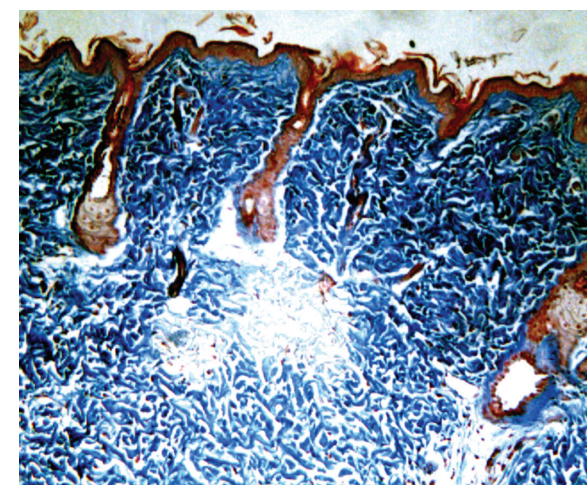

(f)

FIGURE 5: Epithelial tissue of rats in group 1 subjected to second-degree thermal burns. Masson's trichrome staining. 100x Magnification. (a) Normal epithelial tissue with all skin appendages. (b) Animal presenting epithelial tissue with complete destruction of the dermis and epidermis showing exudates albumin/leukocyte/macrophage intense, necrosis, edema, and crust at the 7th day after injury induction. (c) Animal at the 14th day with tissue reepithelialization, moderate autolysis, moderate exudate albumin/leukocyte/macrophage, intense neovascularization, and discrete fibroblast proliferation with the presence of loose collagen and mild fibrosis. (d) Animal at the 21st day with incomplete tissue reepithelialization, mild exudate albumin/leukocyte/macrophage, moderate neovascularization, intense fibroblastic proliferation, and presence of dense collagen, not modeled and moderate fibrosis. (e) Animal at the 28th day with complete tissue epithelialization, exudate albumin/leukocyte/macrophage discrete in the epidermis, moderate fibroblastic proliferation, presence of modeled dense collagen mesh and moderate fibrosis. (f) Animal at the 35th day with complete reepithelialization, mild fibroblastic proliferation, and presence of modeled dense collagen mesh and moderate fibrosis.

3.5. Histopathology. Deep partial thickness burns are injuries that cause partial or total destruction of nerve endings, hair follicles, and sweat glands. On the seventh day was observed intense fibroblastic proliferation, neovascularization, necrosis, and edema. In upper layer of dermis, most hair follicle walls, sebaceous follicles, and sudoriparous glands disappeared and only their residual bodies could be found. Capillary vessels were fractured. The epidermis showed necrosis with infiltration of large numbers of neutrophils and few monocytes, leukocytes, and plasma of the dermis 
(Figure 5(b)). These data are similar to observations reported by Nunes et al. [33] that when evaluating the application of a collagen film containing acid usnic as bandage to treat second-degree thermal burns, an intense inflammatory response after 7 days with presence of neutrophils distributed throughout the length of the burn was found.

With 14 days of experiment, G1 and G2 showed granulation tissue with presence of discrete neovascularization and neoformation of skin appendages. Angiogenesis is essential to restore the supply of nutrients and oxygen during tissue healing [34]. In group 1, an increased number of fibroblasts was observed, and presence of collagen was organized in the lesion center (Figure 5(c)). Experiments performed by Sezer et al. [35] demonstrated that fibroblast and collagen amounts in fucosphere-treated groups increased at day 14 compared to that at day seven, but decreased at day 21 . The reepithelialization time was lower for animals treated with isolectin hydrogel and started around the burn edge on the 14th day. Epithelialization is necessary in the repair of all type of wounds if water tight seal occurs. Protection from fluid and particulate-matter contamination and maintenance of internal milieu are dependent on keratin's physical characteristic [36]. The experimentally induced thermal injuries have been completely reepithelialized in both groups with 35 days.

Histopathology revealed the intense fibroblast proliferation at 21 st day, presence of dense collagen, and not modeled and moderate fibrosis (Figure 5(d)). Collagen deposition in the fibroplasia phase is required for the efficient arrival of fibroblasts to the burn site. Mature fibroblasts produce a delicate matrix that gives mechanical support to the new capillaries [37]. The collagen deposited at the injury site will not have the same unique organization of an intact tissue, being required a period of two months to complete restructure [38]. The decrease in epithelium thickness on the day 21 was considered by Sezer et al. [39] as the result of higher healing rate, particularly on the superficial burn wound treated with chitosan film containing fucoidan.

After 28 days, both G1 and G2 showed gradual decrease in the number of fibroblasts with greater organization of the collagen matrix with reduced inflammatory infiltration (Figure 5(e)). Finally, 35 days after burn procedures, the injured tissue of group 1 is at the stage of maturation and remodeling, with the presence of few fibroblasts and inflammatory cells (Figure 5(f)). The histological analysis of liver sections in group G1 showed no cytotoxic effects resulting from topical application of isolectin hydrogel at the end of treatment after 35 days. These results are consistent with previous studies performed by our group that found the healing action of isoforms 1 and 4 of Cratylia mollis lectin in the repair of skin wounds in normal and immunosuppressed mice [40].

Several studies have confirmed the use of lectins in the immune system activation, enlisting neutrophils through indirect mechanisms [41], promoting proinflammatory effects in polymorphonuclear cells and inducing the cytokines release [42], as well as triggering fibroblasts proliferation [43]. Previous assays accomplished by our group have shown a potential proinflammatory and immunomodulatory activity induced by Cramoll 1,4 lectin. The importance of glycoproteins (including lectins) as components of Aloe vera extract gel has been asserted for promoting wound, burn, and frost-bite healing, and showing anti-inflammatory and antifungal properties [44]. Sell and Costa [45] also described improved effect of PHA lectin in the skin tissue repair process of Wistar rats compared to Triticum vulgaris (WGA) and Artocarpus integrifolia (jacalin) lectin.

\section{Conclusion}

The present study has demonstrated that the regular topical application of Cramoll 1,4 hydrogel containing in the treatment of second-degree burns accelerates the granulation, reepithelialization process, and wound retraction. These results extend the potential of therapeutic applications of isolectin Cramoll 1,4, which can be used in combination with other byproducts in the treatment of thermal burns.

\section{Acknowledgments}

The authors express their gratitude to Fundação de Amparo a Pesquisa do Estado de Pernambuco (FACEPE) for research grants, to Coordenação de Aperfeiçoamento de Pessoal de Nível Superior (CAPES) for financial support, and Adriana Cruz for technical assistance.

\section{References}

[1] L. J. Hellebrekers, "Fisiopatologia da dor em animais e sua conseqüência para a terapia analgésica," in Dor Em Animais, pp. 69-79, Manole, São Paulo, Brazil, 2002.

[2] G. A. Tavares, I. Caracelli, R. Burger, M. T. S. Correia, L. C. B. B. Coelho, and G. Oliva, "Crystallization and preliminary X-ray studies on the lectin from the seeds of Cratylia mollis," Acta Crystallographica Section D, vol. 52, no. 5, pp. 1046-1047, 1996.

[3] V. L. M. Lima, M. T. S. Correia, Y. M. N. Cechinel, C. A. M. Sampaio, J. S. Owen, and L. C. B. B. Coêlho, "Immobilized Cratylia mollis lectin as a potential matrix to isolate plasma glycoproteins, including lecithin-cholesterol acyltransferase," Carbohydrate Polymers, vol. 33, no. 1, pp. 27-32, 1997.

[4] E. I. C. Beltrão, M. T. S. Correia, J. Figueredo-Silva, and L. C. B. B. Coelho, "Binding evaluation of isoform 1 from Cratylia mollis lectin to human mammary tissues," Applied Biochemistry and Biotechnology: Part A, vol. 74, no. 3, pp. 125134, 1998.

[5] E. V. M. Maciel, V. S. Araújo-Filho, M. Nakazawa, Y. M. Gomes, L. C. B. B. Coelho, and M. T. S. Correia, "Mitogenic activity of Cratylia mollis lectin on human lymphocytes," Biologicals, vol. 32, no. 1, pp. 57-60, 2004.

[6] C. M. L. de Melo, M. C. A. B. de Castro, A. P. de Oliveira et al., "Immunomodulatory response of Cramoll 1,4 lectin on experimental lymphocytes," Phytotherapy Research, vol. 24, no. 11, pp. 1631-1636, 2010.

[7] C. A. S. Andrade, M. T. S. Correia, L. C. B. B. Coelho, S. C. Nascimento, and N. S. Santos-Magalhães, "Antitumor activity of Cratylia mollis lectin encapsulated into liposomes," International Journal of Pharmaceutics, vol. 278, no. 2, pp. 435445, 2004. 
[8] L. S. Edelman, "Social and economic factors associated with the risk of burn injury," Burns, vol. 33, no. 8, pp. 958-965, 2007.

[9] G. L. Kramer, T. Lund, and D. Herndon, "Pathophysiology of burn shock and burn edema," in Total Burn Care, D. Herndon, Ed., pp. 78-87, Saunders, Philadelphia, Pa, USA, 2002.

[10] M. C. Guimarães, "História do curativo," in Feridas e Curativos: Uma Forma Simples e Prática de Tratar, Rubio, Ed., pp. 1-3, Rio de Janeiro, Brazil, 2011.

[11] M. T. S. Correia and L. C. B. B. Coelho, "Purification of a glucose/mannose specific lectin, isoform 1, from seeds of Cratylia mollis mart. (Camaratu Bean)," Applied Biochemistry and Biotechnology, vol. 55, no. 3, pp. 261-273, 1995.

[12] B. F. C. Patricio, M. H. M. Lima-Ribeiro, M. T. S. Correia et al., "Radiolabeling of Cramoll 1,4: evaluation of the biodistribution," International Journal of Peptides, vol. 2011, Article ID 945397, 3 pages, 2011.

[13] M. S. Kumar, R. Sripriya, H. V. Raghavan, and P. K. Sehgal, "Wound healing potential of Cassia fistula on infected albino rat model," Journal of Surgical Research, vol. 131, no. 2, pp. 283-289, 2006.

[14] N. Roy, N. Saha, P. Humpolicek, and P. Saha, "Permeability and biocompatibility of novel medicated hydrogel wound dressings," Soft Materials, vol. 8, no. 4, pp. 338-357, 2010.

[15] N. Roy, N. Saha, T. Kitano, and P. Saha, "Novel hydrogels of PVP-CMC and their swelling effect on viscoelastic properties," Journal of Applied Polymer Science, vol. 117, no. 3, pp. 17031710, 2010.

[16] A. Burd, "Evaluating the use of hydrogel sheet dressings in comprehensive burn wound care," Ostomy Wound Management, vol. 53, no. 3, pp. 52-62, 2007.

[17] E. Osti, "Cutaneous burns treated with hydrogel (Burnshield) and a semipermeable adhesive film," Archives of Surgery, vol. 141, no. 1, pp. 39-42, 2006.

[18] J. G. Hancok and J. L. Jorizzo, "Burns," in Manual of Dermatologic Therapeutics, K. A. Arndt and J. T. S. Hsu, Eds., Lippincott Williams \& Wilkins, Philadelphia, Pa, USA, 7th edition, 2007.

[19] A. D. Sezer, E. Cevher, F. Hatipoğlu, Z. Oğurtan, A. L. Baş, and J. Akbuğa, "Preparation of fucoidan-chitosan hydrogel and its application as burn healing accelerator on rabbits," Biological and Pharmaceutical Bulletin, vol. 31, no. 12, pp. 2326-2333, 2008.

[20] N. S. Anuar, S. S. Zahari, I. A. Taib, and M. T. Rahman, "Effect of green and ripe Carica papaya epicarp extracts on wound healing and during pregnancy," Food and Chemical Toxicology, vol. 46, no. 7, pp. 2384-2389, 2008.

[21] R. O’Leary, E. J. Wood, and P. J. Guillou, "Pathological scarring: strategic interventions," European Journal of Surgery, vol. 168, no. 10, pp. 523-534, 2002.

[22] T. Yasuoka, M. Sasaki, T. Fukunaga et al., "The effects of lectins on indomethacin-induced small intestinal ulceration," International Journal of Experimental Pathology, vol. 84, no. 5, pp. 231-237, 2003.

[23] J. B. Messias, M. C. M. Caraciolo, I. M. Oliveira, U. R. Montarroyos, M. O. Guerra, and I. A. Souza, "Parâmetros hematológicos de Rattus norvegicus obtidos através de métodos automatizado e não automatizado," Medicina Veterinaria, vol. 3, no. 2, pp. 1-8, 2009.
[24] G. D. Carvalho, A. P. B. Masseno, M. S. Zanini et al., "Avaliação clínica de ratos de laboratório (Rattus novergicus linhagem Wistar): parâmetros sanitários, biológicos e fisiológicos," Ceres, vol. 56, no. 1, pp. 51-57, 2009.

[25] D. C. Gore, D. L. Chinkes, D. W. Hart, S. E. Wolf, D. N. Herndon, and A. P. Sanford, "Hyperglycemia exacerbates muscle protein catabolism in burn-injured patients," Critical Care Medicine, vol. 30, no. 11, pp. 2438-2442, 2002.

[26] A. A. Ferrando, M. Sheffield-Moore, S. E. Wolf, D. N. Herndon, and R. R. Wolfe, "Testosterone administration in severe burns ameliorates muscle catabolism," Critical Care Medicine, vol. 29, no. 10, pp. 1936-1942, 2001.

[27] Y. K. Youn, C. LaLonde, and R. Demling, "The role of mediators in the response to thermal injury," World Journal of Surgery, vol. 16, no. 1, pp. 30-36, 1992.

[28] C. J. Beukelman, A. J. J. van den Berg, M. J. Hoekstra, R. Uhl, K. Reimer, and S. Mueller, "Anti-inflammatory properties of a liposomal hydrogel with povidone-iodine (Repithel ${ }^{\circledR}$ ) for wound healing in vitro," Burns, vol. 34, no. 6, pp. 845-855, 2008.

[29] M. Møller-Kristensen, M. R. Hamblin, S. Thiel, J. C. Jensenius, and K. Takahashi, "Burn injury reveals altered phenotype in mannan-binding lectin-deficient mice," Journal of Investigative Dermatology, vol. 127, no. 6, pp. 1524-1531, 2007.

[30] R. A. Moreira, I. L. Ainouz, J. T. de Oliveira, and B. S. Cavada, "Plant lectins, chemical and biological aspects," Memorias do Instituto Oswaldo Cruz, vol. 86, pp. 211-218, 1991.

[31] B. S. Cavada, C. F. Santos, T. B. Grangeiro et al., "Purification and characterization of a lectin from seeds of Vatairea macrocarpa duke," Phytochemistry, vol. 49, no. 3, pp. 675-680, 1998.

[32] H. J. Gabius and S. Gabius, Glycosciences: Status and Perspectives, Wiley-VCH, New York, NY, USA, 2nd edition, 2002.

[33] P. S. Nunes, R. L. C. Albuquerque-Jnior, D. R. R. Cavalcante et al., "Collagen-based films containing liposome-loaded usnic acid as dressing for dermal burn healing," Journal of Biomedicine and Biotechnology, vol. 2011, Article ID 761593, 9 pages, 2011.

[34] S. M. Bauer, R. J. Bauer, and O. C. Velazquez, "Angiogenesis, vasculogenesis, and induction of healing in chronic wounds," Vascular and Endovascular Surgery, vol. 39, no. 4, pp. 293-306, 2005.

[35] A. D. Sezer, E. Cevher, F. Hatipoğlu, Z. Oğurtan, A. L. Baş, and J. Akbuğa, "The use of fucosphere in the treatment of dermal burns in rabbits," European Journal of Pharmaceutics and Biopharmaceutics, vol. 69, no. 1, pp. 189-198, 2008.

[36] E. E. Peacock Jr., "Wound healing and wound care," in Principles of Surgery, S. I. Schwartz, Ed., p. 292, McGraw-Hill, Singapore, 4th edition, 1985.

[37] P. L. Williams, L. H. Bannister, M. N. Berry et al., Gray's Anatomy, Churchill Livingstone, Philadelphia, Pa, USA, 1995.

[38] J. Li, J. Chen, and R. Kirsner, "Pathophysiology of acute wound healing," Clinics in Dermatology, vol. 25, no. 1, pp. 9-18, 2007.

[39] A. D. Sezer, F. Hatipoğlu, E. Cevher, Z. Oğurtan, A. L. Baş, and J. Akbuğa, "Chitosan film containing fucoidan as a wound dressing for dermal burn healing: preparation and in vitro/in vivo evaluation," AAPS PharmSciTech, vol. 8, no. 2, article 39, pp. E94-E101, 2007.

[40] C. M. L. D. Melo, C. S. Porto, and M. R. Melo Jr., "Healing activity induced by Cramoll 1,4 lectin in healthy and 
immunocompromised mice," International Journal of Pharmaceutics, vol. 408, no. 1-2, pp. 113-119, 2011.

[41] A. M. S. Assreuy, N. M. N. Alencar, B. S. Cavada et al., "Porcine spermadhesin PSP-I/PSP-II stimulates macrophages to release a neutrophil chemotactic substance: modulation by mast cells," Biology of Reproduction, vol. 68, no. 5, pp. 18361841, 2003.

[42] V. B. M. Alencar, N. M. N. Alencar, A. M. S. Assreuy et al., "Pro-inflammatory effect of Arum maculatum lectin and role of resident cells," International Journal of Biochemistry and Cell Biology, vol. 37, no. 9, pp. 1805-1814, 2005.

[43] A. M. Sell and C. P. da Costa, "Effects of plant lectins on in vitro fibroblast proliferation," Brazilian Archives of Biology and Technology, vol. 46, no. 3, pp. 349-354, 2003.

[44] S. Choi and M. H. Chung, "A review on the relationship between Aloe vera components and their biologic effects," Seminars in Integrative Medicine, vol. 1, no. 1, pp. 53-62, 2003.

[45] A. M. Sell and C. P. Costa, "Efeito inflamatório local induzido pelas lectinas PHA, WGA e Jacalina," Arquivos de Ciências da Saúde, vol. 6, no. 1, pp. 47-51, 2002. 


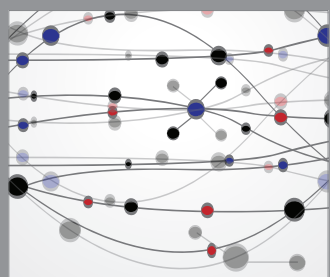

The Scientific World Journal
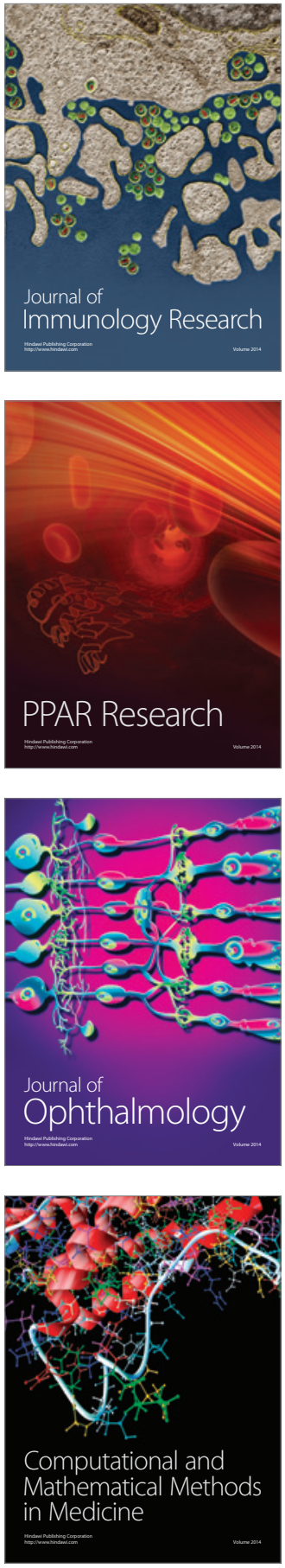

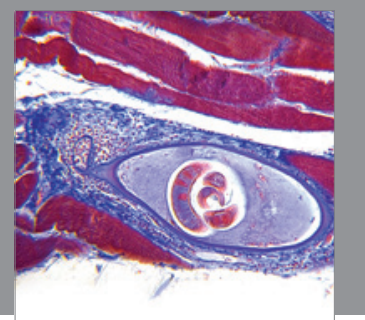

Gastroenterology

Research and Practice
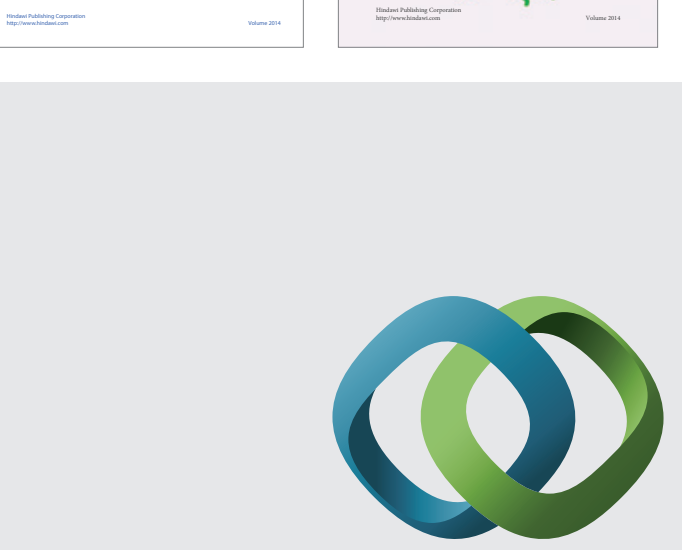

\section{Hindawi}

Submit your manuscripts at

http://www.hindawi.com
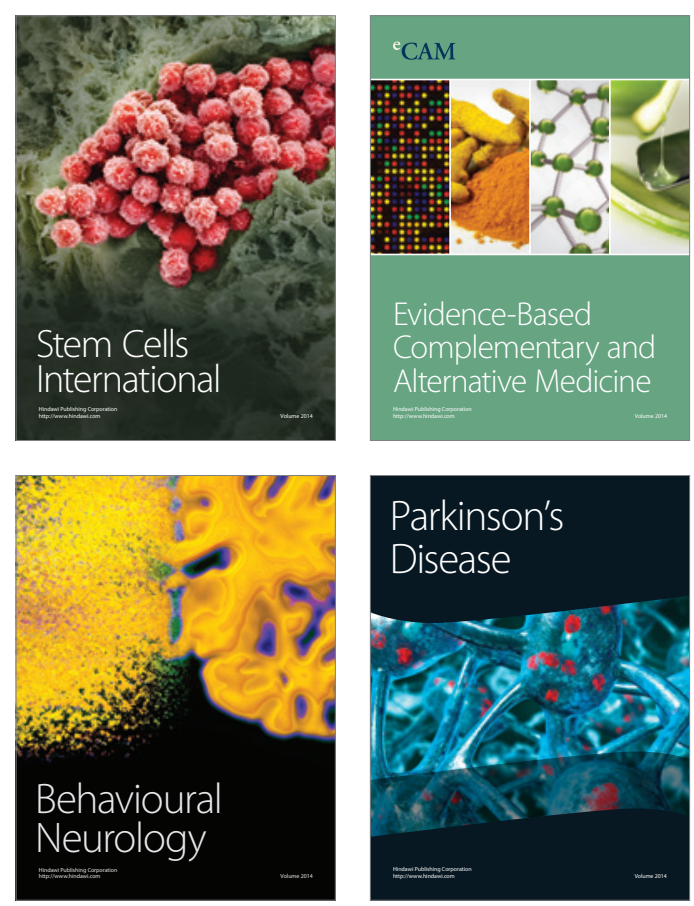

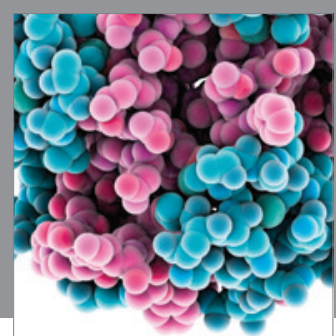

Journal of
Diabetes Research

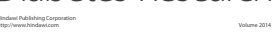

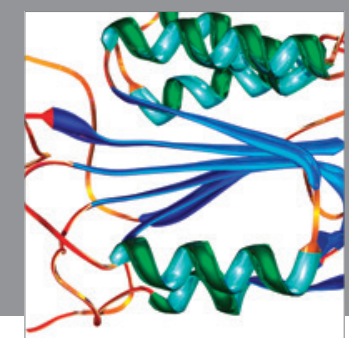

Disease Markers
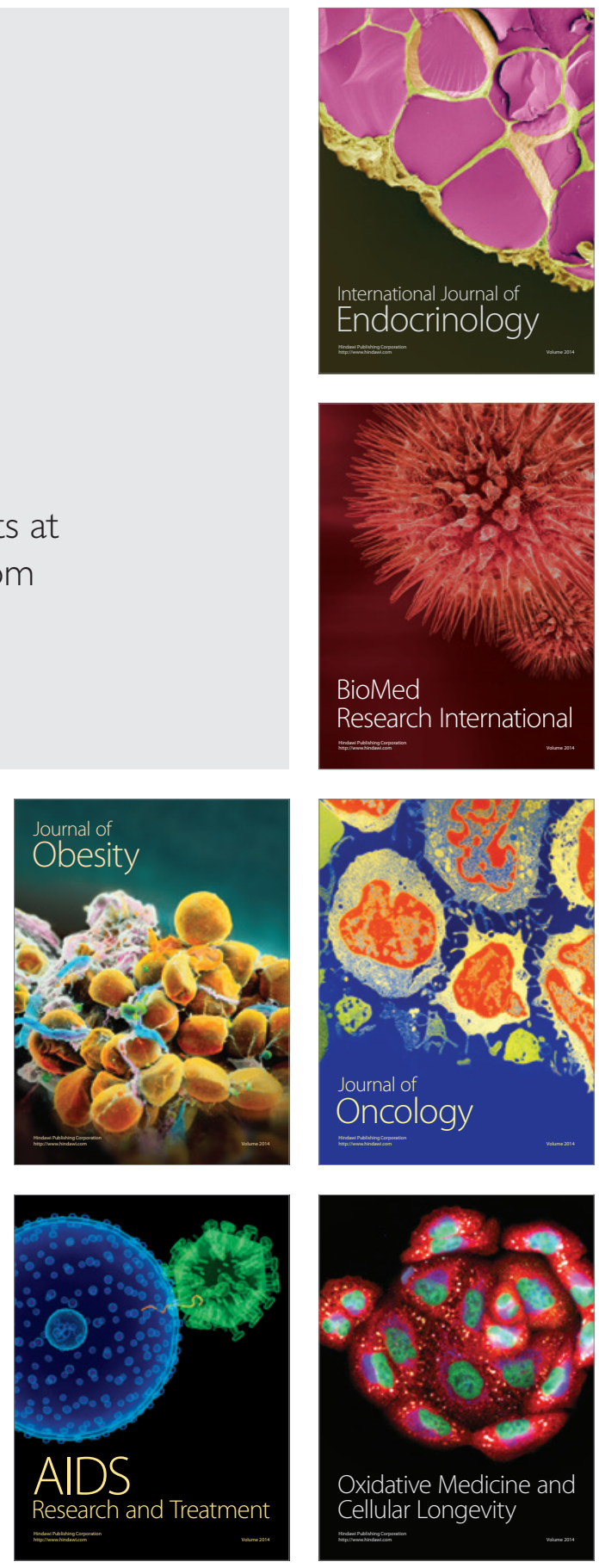